\title{
Will CULPRIT-SHOCK change my practice? The CULPRIT- SHOCK trial: culprit lesion-only PCI vs. multivessel PCI in patients with acute myocardial infarction and cardiogenic shock
}

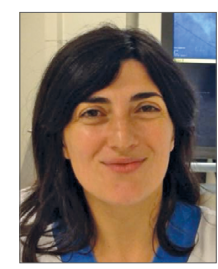

Giovanna Sarno $^{1 *}, \mathrm{MD}, \mathrm{PhD}$; Alaide Chieffo ${ }^{2}, \mathrm{MD}$; Peter Ludman ${ }^{3}, \mathrm{MD}, \mathrm{PhD}$; Adam Witkowski ${ }^{4}, \mathrm{MD}, \mathrm{PhD}$; Christian Spaulding ${ }^{5}, \mathrm{MD}$, PhD; Stefan James ${ }^{1}, \mathrm{MD}, \mathrm{PhD}$

1. Department of Medical Sciences, Cardiology and Uppsala Clinical Research Center, Uppsala University, Uppsala, Sweden;

2. Interventional Cardiology Unit, San Raffaele Hospital, Milan, Italy; 3. Department of Cardiology, Queen Elizabeth Hospital, Birmingham, United Kingdom; 4. Department of Interventional Cardiology \& Angiology, Institute of Cardiology, Warsaw, Poland; 5. Department of Cardiology, European Hospital Georges Pompidou and Paris-Descartes University, Paris, France

\section{Introduction to the session}

This summary report aims to capture the content of the session at EuroPCR 2018 that reviewed the implications for clinical practice of the CULPRIT-SHOCK trial, in order to share a critical analysis of the trial and report the views expressed in the interactive discussion. This article does not constitute an independent review of the topic by the authors.

The CULPRIT-SHOCK study ${ }^{1}$ tested the hypothesis that percutaneous coronary intervention (PCI) of culprit lesion only, with the option of staged revascularisation of non-culprit lesions, would result in better clinical outcomes than immediate multivessel PCI in patients with multivessel coronary artery disease and acute myocardial infarction with cardiogenic shock.

Trial headlines indicated that this study is a landmark study and a "game changer" for clinical practice, similarly to the IABPSHOCK $^{2}$ study that has resulted in a large reduction in the use of intra-aortic balloon pump (IABP) in patients with cardiogenic shock. IABP is nevertheless still used in $25-40 \%$ of cardiogenic shock cases. Will the results of CULPRIT-SHOCK follow the same path or will they change our practice?

\section{The case presentation}

A 67-year-old man was admitted to a tertiary hospital with nonST-segment elevation myocardial infarction (NSTEMI) complicated by cardiogenic shock during the first day of admission, prior to revascularisation.

The coronary angiogram showed a distal left main with some haziness due to a large amount of thrombus involving mainly the proximal left anterior descending artery (LAD), which was patent with Thrombolysis In Myocardial Infarction (TIMI) flow 2, and a totally occluded left circumflex atery (LCx), with no distal collateral filling.

\section{Background: what was known before the CULPRIT-SHOCK trial?}

Previous studies on cardiogenic shock have shown a gradual increase over recent years, from about 7 to $10 \%$, of patients with STEMI and cardiogenic shock. Despite early revascularisation, mortality remains extremely high, particularly in patients older than 75 years. The original SHOCK trial ${ }^{3}$ showed that early revascularisation by PCI or coronary artery bypass grafting $(\mathrm{CABG})$ reduced mortality when compared with the initial

*Corresponding author: Uppsala University Hospital, Sjukhusvägen, 75185 Uppsala, Sweden.

E-mail: giovanna.sarno@ucr.uu.se 
medical stabilisation arm. In this study, 36\% of patients in the revascularisation arm were treated by $\mathrm{CABG}$ with a median delay of 2.7 hours, and $64 \%$ by PCI with a median delay of 54 minutes. Though the trial spanned the era of the introduction of stents and GP IIb/IIIa inhibitors, there was no trend to additional benefit with the newly introduced PCI strategies and the one-year-mortality was similar over time ${ }^{4}$.

Recent data from a large German registry ${ }^{5}$ showed that, in patients with cardiogenic shock, the time elapsing from the first medical contact to primary PCI was a strong predictor of an adverse outcome. Hence, special efforts to shorten contact-to-balloon time should be implemented, especially in these high-risk patients.

Two recent meta-analyses ${ }^{6,7}$ of 10 observational studies concluded that, in patients with acute myocardial infarction and multivessel coronary artery disease complicated by cardiogenic shock, culprit-only PCI was associated with short-term, but not long-term benefit.

However, in spite of almost two decades of research since the SHOCK trial, no other strategies have been shown to improve outcomes convincingly, including trials of new pharmacological approaches or mechanical circulatory support ${ }^{2}$.

\section{Trial analysis: summary of the trialists' critical review}

The study design (Figure 1) and results of the CULPRIT-SHOCK trial (Figure 2A, Figure 2B) are included.

In this multicentre trial, 706 patients who had multivessel disease, acute myocardial infarction, and cardiogenic shock were randomly assigned to one of two initial revascularisation strategies: either PCI of the culprit lesion only, with the option of staged revascularisation of non-culprit lesions, or immediate multivessel PCI.
At 30 days, the composite primary endpoint of death or renal replacement therapy had occurred in 158 of the 344 patients (45.9\%) in the culprit lesion-only PCI group, and in 189 of the 341 patients $(55.4 \%)$ in the multivessel PCI group (relative risk, $0.83,95 \%$ confidence interval $[\mathrm{CI}]: 0.71$ to $0.96 ; \mathrm{p}=0.01)$. The reduced composite endpoint in the culprit lesion-only PCI group was mainly driven by a lower mortality at 30 days. The relative risk of death in the culprit lesion-only PCI group as compared with the multivessel PCI group was 0.84 (95\% CI: 0.72 to 0.98 ; $\mathrm{p}=0.03$ ), and the relative risk of renal replacement therapy was 0.71 (95\% CI: 0.49 to 1.03 ; $\mathrm{p}=0.07$ ). The time to haemodynamic stabilisation, the need for catecholamine therapy and the duration of such therapy, the levels of troponin $\mathrm{T}$ and creatinine kinase, and the rates of bleeding and stroke did not differ significantly between the two groups.

In contrast with previous trials involving highly selected patients with stable infarction, this trial did not specify the presence of a chronic total occlusion as an exclusion criterion. Therefore, in the multivessel PCI group, immediate recanalisation of a chronic total occlusion was recommended. However, it was also advised to limit the total dose of contrast to $300 \mathrm{ml}$. Complete revascularisation was achieved in $81 \%$ of the patients in the multivessel PCI group.

It was concluded that this study has definitively challenged the most recent ESC guidelines, suggesting that PCI of the nonculprit vessel should be considered in STEMI patients with cardiogenic shock (class IIa, level of evidence C) ${ }^{8}$. Moreover, mechanical circulatory support was used in only $\sim 28 \%$ of the patients and IABP was used in $27 \%$ in the multivessel PCI group. It is still a matter of debate whether a higher use of mechanical circulatory support could determine better outcomes in these patients.

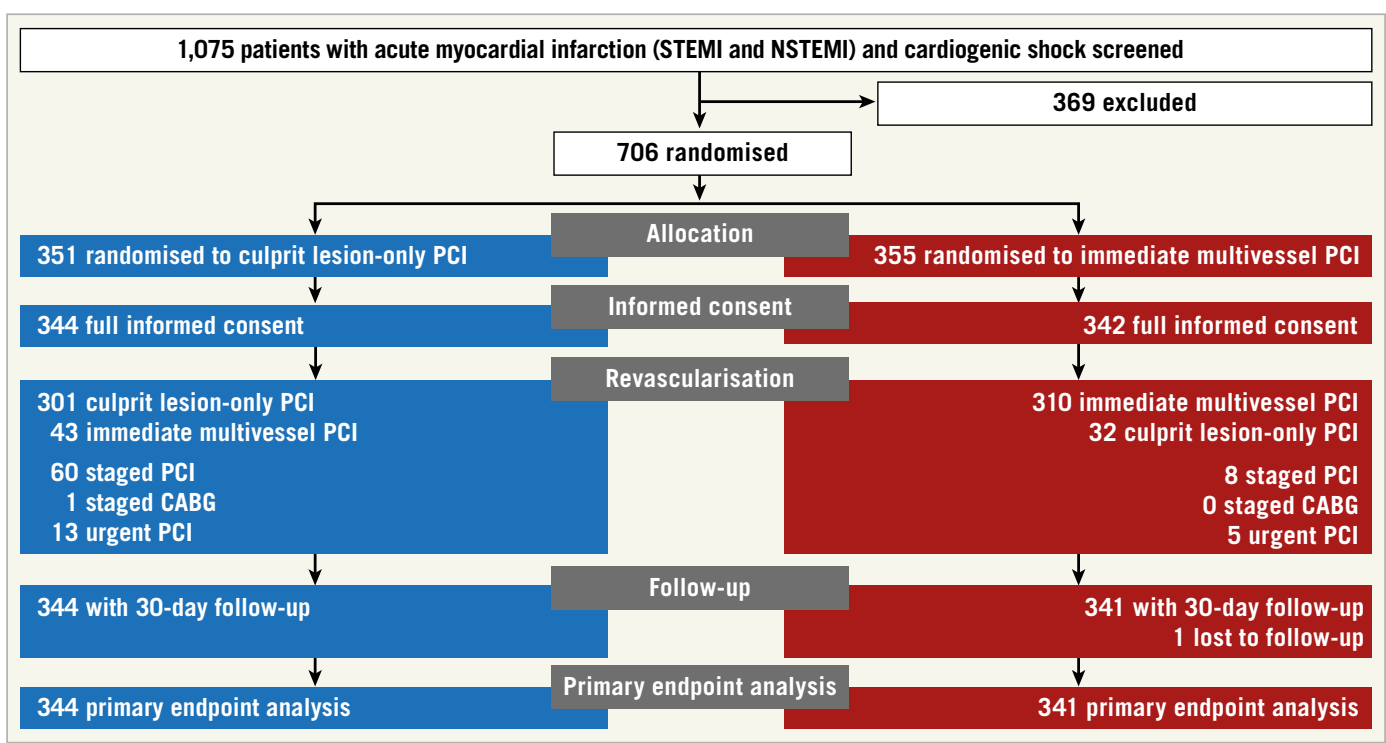

Figure 1. Study flow chart. 
A

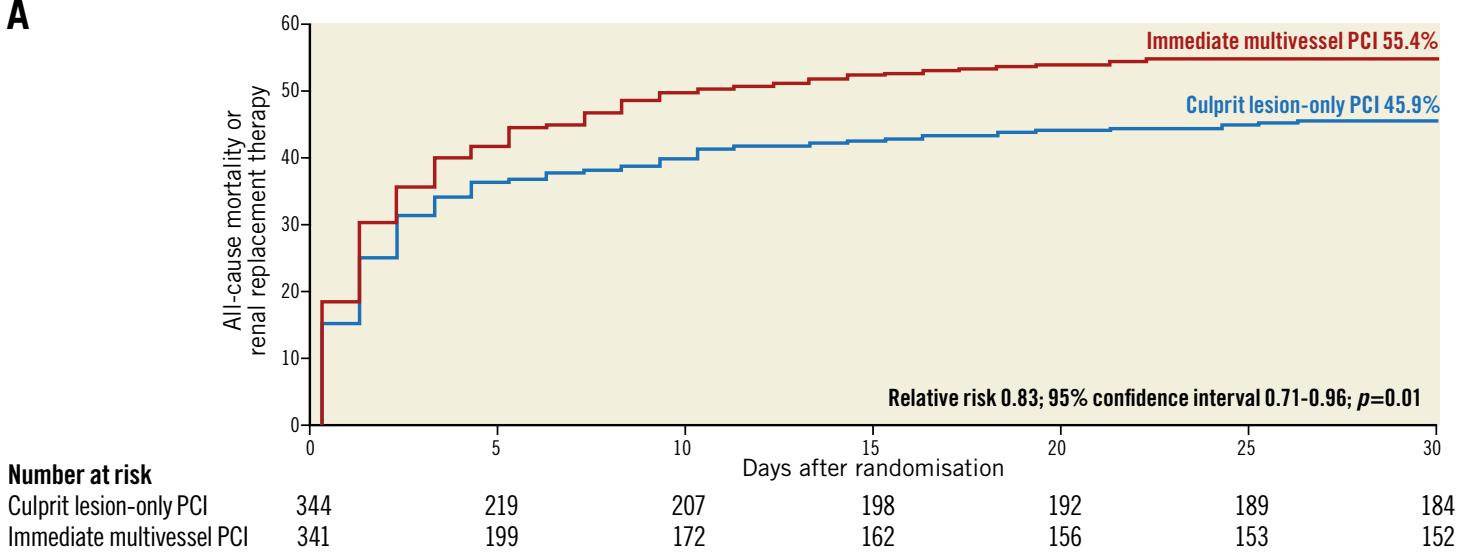

B

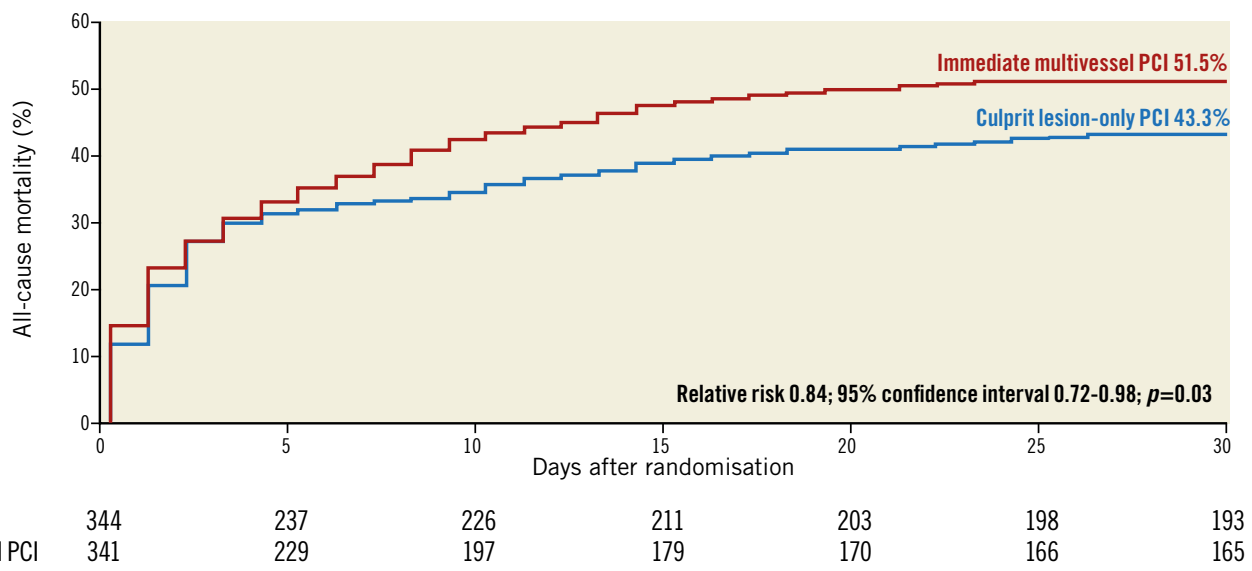

Figure 2. Results of the CULPRIT-SHOCK trial. A) Primary composite endpoint at 30 days. B) Mortality at 30 days.

\section{The case resolution and the practitioner's view}

Treatment of the case presentation patient was revealed: PCI with manual thrombectomy in the LAD, followed by left main-LAD and LCx T-stenting with a good angiographic result. An IABP was introduced after the PCI. The patient died after three days in the intensive care unit. Despite increasing catecholamine infusion and IABP, the systolic blood pressure was $80 \mathrm{mmHg}$ and the LV systolic function remained severely depressed (EF: 10\% by transthoracic echocardiography [TTE]). The patient passed away from cardiac arrest after ineffective resuscitation attempts.

It was mentioned again that IABP is not helpful in cardiogenic shock, as shown in the IABP-II trial; however, not all the interventional centres have access to the different mechanical circulatory support alternatives. Manual thrombectomy was used in this case, although routine thrombectomy is discouraged in the 2017 ESC Guidelines (class III recommendation) after the results of the TASTE $^{9}$ and TOTAL studies ${ }^{10}$. Of note, even in patients with very high thrombotic risk or high thrombus burden from the TASTE subgroup analyses, no benefits of manual thrombectomy were observed.

Further discussion focused on the possible treatment strategies for the case patient. Multivessel PCI seemed to be the most reasonable revascularisation strategy in this case. The audience and the panel were split among the possibilities of using mechanical circulatory assistance by IABP, ECMO or Impella ${ }^{\circledR}$ (Abiomed, Danvers, MA, USA). At the moment there is little supporting evidence, and future randomised studies would be required to evaluate the potential benefit of early application of the different available mechanical circulatory support systems. The best timing also remains to be defined - whether just before or just after PCI.

\section{Conclusions}

The results of this trial support the clinical practice where PCI in culprit lesion-only with possible staged revascularisation is the most commonly selected option. The recent available randomised trials ${ }^{11,12}$ that have shown a benefit of multivessel PCI in STEMI patients have excluded patients with cardiogenic shock. CULPRIT-SHOCK was a randomised trial including challenging real-life patients with a "real-life" primary endpoint that has been shown to be significantly improved by PCI of the culprit lesion only. The results of this study have been integrated into the recently published update of the ESC guidelines ${ }^{13}$ with the following summary key points.

In patients with cardiogenic shock complicating STEMI and NSTEMI:

- Primary PCI should routinely be restricted to the infarct-related artery (IRA). 
- Immediate multivessel PCI may be justified if the IRA is difficult to identify or incorrectly defined initially or when multiple culprit lesions are identified.

- Immediate multivessel PCI may be justified in selected cases in which there is a flow-limiting non-IRA with very severe stenosis irrigating a large myocardial area.

- Staged non-IRA PCI might be an option, carefully balancing the benefits and risks.

\section{Conflict of interest statement}

G. Sarno has received institutional research support from Boston Scientific. A. Chieffo has received speaker's fees from Abiomed. C. Spaulding has received speaker's fees from Abiomed and is a consultant for Medtronic. S. James has received institutional research support and lecture fees from Boston Scientific, Abbott Vascular, Biotronik and Terumo. The other authors have no conflicts of interest to declare.

\section{References}

1. Thiele H, Akin I, Sandri M, Fuernau G, de Waha S, MeyerSaraei R, Nordbeck P, Geisler T, Landmesser U, Skurk C, Fach A, Lapp H, Piek JJ, Noc M, Goslar T, Felix SB, Maier LS, Stepinska J, Oldroyd K, Serpytis P, Montalescot G, Barthelemy O, Huber K, Windecker S, Savonitto S, Torremante P, Vrints C, Schneider S, Desch S, Zeymer U; CULPRIT-SHOCK Investigators. PCI Strategies in Patients with Acute Myocardial Infarction and Cardiogenic Shock. N Engl J Med. 2017;377:2419-32.

2. Thiele H, Zeymer U, Neumann FJ, Ferenc M, Olbrich HG, Hausleiter J, de Waha A, Richardt G, Hennersdorf M, Empen K, Fuernau G, Desch S, Eitel I, Hambrecht R, Lauer B, Böhm M, Ebelt H, Schneider S, Werdan K, Schuler G; Intraaortic Balloon Pump in cardiogenic shock (IABP-SHOCK II) trial investigators. Intra-aortic balloon counterpulsation in acute myocardial infarction complicated by cardiogenic shock (IABP-SHOCK II): final 12 month results of a randomised, open-label trial. Lancet. 2013;382:1638-45.

3. Hochman JS, Sleeper LA, Webb JG, Sanborn TA, White HD, Talley JD, Buller CE, Jacobs AK, Slater JN, Col J, McKinlay SM, LeJemtel TH. Early revascularization in acute myocardial infarction complicated by cardiogenic shock. SHOCK Investigators. Should We Emergently Revascularize Occluded Coronaries for Cardiogenic Shock. N Engl J Med. 1999;341:625-34.

4. Webb JG, Lowe AM, Sanborn TA, White HD, Sleeper LA, Carere RG, Buller CE, Wong SC, Boland J, Dzavik V, Porway M, Pate G, Bergman G, Hochman JS; SHOCK Investigators. Percutaneous coronary intervention for cardiogenic shock in the SHOCK trial. J Am Coll Cardiol. 2003;42:1380-6.

5. Scholz KH, Maier SKG, Maier LS, Lengenfelder B, Jacobshagen C, Jung J, Fleischmann C, Werner GS, Olbrich HG, Ott R, Mudra H, Seidl K, Schulze PC, Weiss C, Haimerl J, Friede T, Meyer T. Impact of treatment delay on mortality in ST-segment elevation myocardial infarction (STEMI) patients presenting with and without haemodynamic instability: results from the German prospective, multicentre FITT-STEMI trial. Eur Heart J. 2018;39:1065-74.
6. Tarantini G, D’Amico G, Tellaroli P, Colombo C, Brener SJ. Meta-Analysis of the Optimal Percutaneous Revascularization Strategy in Patients With Acute Myocardial Infarction, Cardiogenic Shock, and Multivessel Coronary Artery Disease. Am J Cardiol. 2017;119:1525-31.

7. de Waha S, Eitel I, Desch S, Fuernau G, Pöss J, Schuler G, Thiele H. Impact of multivessel coronary artery disease on reperfusion success in patients with ST-elevation myocardial infarction: A substudy of the AIDA STEMI trial. Eur Heart J Acute Cardiovasc Care. 2017;6:592-600.

8. Ibanez B, James S, Agewall S, Antunes MJ, BucciarelliDucci C, Bueno H, Caforio ALP, Crea F, Goudevenos JA, Halvorsen S, Hindricks G, Kastrati A, Lenzen MJ, Prescott E, Roffi M, Valgimigli M, Varenhorst C, Vranckx P, Widimsky P; ESC Scientific Document Group. 2017 ESC Guidelines for the management of acute myocardial infarction in patients presenting with ST-segment elevation: The Task Force for the management of acute myocardial infarction in patients presenting with ST-segment elevation of the European Society of Cardiology (ESC). Eur Heart J. 2018;39:119-77.

9. Fröbert O, Lagerqvist B, Olivecrona GK, Omerovic E, Gudnason T, Maeng M, Aasa M, Angeras O, Calais F, Danielewicz M, Erlinge D, Hellsten L, Jensen U, Johansson AC, Karegren A, Nilsson J, Robertson L, Sandhall L, Sjögren I, Ostlund O, Harnek J, James SK; TASTE Trial. Thrombus aspiration during ST-segment elevation myocardial infarction. $N$ Engl J Med. 2013;369:1587-97.

10. Jolly SS, Cairns JA, Yusuf S, Meeks B, Pogue J, Rokoss MJ, Kedev S, Thabane L, Stankovic G, Moreno R, Gershlick A, Chowdhary S, Lavi S, Niemelä K, Steg PG, Bernat I, Xu Y, Cantor WJ, Overgaard CB, Naber CK, Cheema AN, Welsh RC, Bertrand OF, Avezum A, Bhindi R, Pancholy S, Rao SV, Natarajan MK, ten Berg JM, Shestakovska O, Gao P, Widimsky P, Dzavik V; TOTAL Investigators. Randomized trial of primary PCI with or without routine manual thrombectomy. N Engl J Med. 2015; 372:1389-98.

11. Wald DS, Morris JK, Wald NJ, Chase AJ, Edwards RJ, Hughes LO, Berry C, Oldroyd KG; PRAMI Investigators. Randomized trial of preventive angioplasty in myocardial infarction. N Engl J Med. 2013;369:1115-23.

12. GershlickAH, Khan JN, Kelly DJ, Greenwood JP, Sasikaran T, Curzen N, Blackman DJ, Dalby M, Fairbrother KL, Banya W, Wang D, Flather M, Hetherington SL, Kelion AD, Talwar S, Gunning M, Hall R, Swanton H, McCann GP. Randomized trial of complete versus lesion-only revascularization in patients undergoing primary percutaneous coronary intervention for STEMI and multivessel disease: the CvLPRIT trial. J Am Coll Cardiol. 2015;65: 963-72.

13. Ibanez B, Halvorsen S, Roffi M, Bueno $H$, Thiele $H$, Vranckx P, Neumann FJ, Windecker S, James S. Integrating the results of the CULPRIT-SHOCK trial in the 2017 ESC ST-elevation myocardial infarction guidelines: viewpoint of the task force. Eur Heart J. 2018 May 29. [Epub ahead of print]. 